\title{
Neck of the Humerus, Surgical
}

National Cancer Institute

\section{Source}

National Cancer Institute. Neck of the Humerus, Surgical. NCI Thesaurus. Code C140468.

The constriction on the proximal end of the humerus just below the tuberosities of the humerus. 